\title{
APORTACIONES DE UN CLUB DE LECTURA ESCOLAR A LA LECTURA POR PLACER
}

\section{Carmen Álvarez-Álvarez y Julián Pascual-Díez}

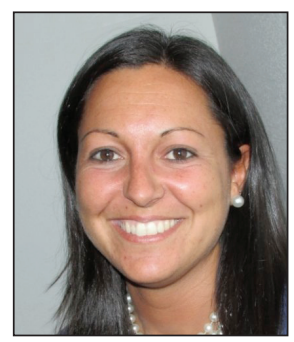

Carmen Álvarez-Álvarez es doctora en pedagogía y profesora ayudante doctor en la Facultad de Educación de la Universidad de Cantabria. Sus líneas de investigación son las relaciones teoríapráctica, la animación a la lectura, la innovación escolar y las comunidades de aprendizaje. http://orcid.org/0000-0002-8160-2286

Universidad de Cantabria, Departamento de Educación Av. Castros, s/n. 39005 Santander, España carmen.alvarez@unican.es

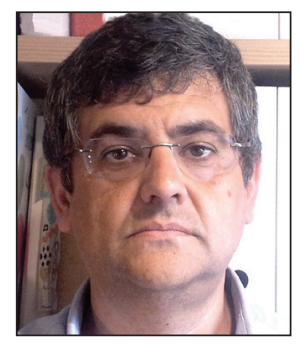

Julián Pascual-Díez es doctor en pedagogía y profesor titular de didáctica de la lengua y literatura en la Facultad de Educación de la Universidad de Oviedo. Sus líneas de investigación son: didáctica de la literatura, promoción de la lectura y formación del profesorado.

http://orcid.org/0000-0003-2694-9647

Universidad de Oviedo, Departamento de Educación Aniceto Sela, s/n. 33005 Oviedo, España jpascual@uniovi.es

\section{Resumen}

Uno de los principales retos en el trabajo de la lectura en los centros educativos es el cultivo de la lectura por placer en los niños. Se presenta un estudio de caso único realizado en un club de lectura escolar en España que ha logrado conseguir este objetivo y ha recibido una valoración muy positiva por parte de los participantes. Las razones de su éxito residen fundamentalmente en cuatro claves: planificación, lectura dialógica, formación crítica y educación en valores.

\section{Palabras clave}

Animación a la lectura, Hábito lector, Club de lectura, Lectura dialógica, Estudio de caso, Escuela primaria, Enseñanza primaria.

\section{Title: Contributions of a school book club to encourage reading for pleasure}

\section{Abstract}

Currently one of the main challenges in the work of promoting reading in schools is the cultivation of children's enjoyment of reading. We present a unique case study in a school reading club in Spain that has managed to achieve that goal and has received a very positive assessment from participants. The reasons for its success mainly reside in four key areas: planning, dialogic reading, critical thinking and values education.

\section{Keywords}

Encourage to reading, Reading habit, Book club, Reading club, Dialogic reading, Case study, Children, Primary school.

Álvarez-Álvarez, Carmen; Pascual-Díez, Julián (2014). “Aportaciones de un club de lectura escolar a la lectura por placer". El profesional de la información, v. 23, n. 6, noviembre-diciembre, pp. 625-631.

http://dx.doi.org/10.3145/epi.2014.nov.10

\section{Introducción}

La educación lectora no sólo trata de formar personas para que sepan leer cada vez mejor, sino también para que, en lo posible, quieran leer, estén motivadas hacia la lectura y puedan integrarla en su vida. A pesar de las interesantes propuestas didácticas, materiales formativos, portales digitales, cursos, seminarios, convocatorias de premios y publicaciones de buenas prácticas que se han elaborado durante los últimos años a nivel autonómico y estatal, es mucho el camino que queda por recorrer tanto en políticas educativas como en el ámbito de la investigación e innovación en los centros educativos. 
Las actividades literarias más tradicionales plantean tareas posteriores a la lectura habitualmente orientadas al análisis formal y estructural de los textos con preguntas de comprensión no siempre significativas, sin contemplar el comentario de las emociones o actitudes que suscitan los textos.

Uno de los aspectos de las bibliotecas escolares más valorados por la comunidad educativa es su capacidad para estimular el gusto por la lectura (Baró; Mañà, 2013). Uno de los medios más adecuados para estimular la lectura por placer y las actividades de aprendizaje comunicativas son los clubs de lectura escolares (Arana-Palacios; Galindo-Lizaldre, 2009; Jiménez-Fernández; Cremades-García, 2013). Un club de lectura es "una obra en movimiento que se recorre de la mano de un libro, un lector y un conductor" (Carreño, 2012, p. 31); supone "una ocasión de leer con los demás, un deseo de compartir lecturas, un modo dialogal de extender la mirada y afinar los oídos" (Mata, 2008, p. 82). La interacción del grupo y la escucha a los compañeros favorece la implicación personal de los participantes y discusiones que ayudan a conectar la literatura con la vida (Gritter, 2011). Los clubs de lectura escolares pueden favorecer una lectura crítica (Atwell, 2007; Cassany, 2008) y contribuir al desarrollo de niveles de alfabetización superior (Olson, 2009). Además, pueden potenciar la función transformadora que la biblioteca debería desempeñar en la educación, al posibilitar la interacción y el aprendizaje dialógico (Gómez-Hernández, 2013). A pesar de ello, la mayor parte de los centros educativos españoles carecen de clubs de lectura.

Las sesiones de los clubs de lectura escolares siguen unas formas habituales: se selecciona un libro, se determina un tiempo para su lectura y se fija una reunión posterior para comentarlo

Las sesiones de los clubs de lectura escolares siguen unas formas habituales: se selecciona un libro, se determina un tiempo para su lectura y se fija una reunión posterior para comentarlo. En estas reuniones suelen abordarse pasajes destacados del libro, se cuestionan comportamientos de los protagonistas, se plantean experiencias personales y se genera un intercambio rico en pensamientos y reflexiones.
La formación de niños lectores puede investigarse siguiendo numerosos enfoques metodológicos. En este artículo se presentan los resultados del estudio de caso de un club de lectura escolar en el marco de una investigación-acción. La relevancia de la investigación-acción radica en su interés por conocer y entender los problemas cotidianos reales que viven los docentes, con el objetivo de analizar la propia práctica para comprenderla y transformarla, favoreciendo el desarrollo profesional del profesorado, que se va emancipando a medida que va llevando a efecto estos procesos (Whitehead, 2009).

El objetivo general de la investigación es analizar la contribución de un club de lectura, organizado en la biblioteca del centro, al desarrollo de la lectura por placer del alumnado. La hipótesis de partida es que ello puede ocurrir como consecuencia de la interrelación que se establece entre las ideas del lector, las ideas que transmite la lectura de la obra en solitario y las ideas de los compañeros expuestas en las tertulias que se organizan.

\section{Método}

\subsection{Participantes y lecturas}

En este estudio de caso participó un grupo de 24 estudiantes de tercer ciclo de educación primaria (10 niños y 15 niñas de 11-12 años y clase social media-baja), que pertenecían al club de lectura escolar de un colegio público de educación infantil y primaria de Asturias, durante el curso 2009-2010.

Los coordinadores fueron una profesora universitaria de la Facultad de Pedagogía externa al centro (que ya había participado en dos ediciones anteriores del club de lectura) y un alumno de esa misma Facultad. Ellos seleccionaron cinco obras narrativas, motivados por su carácter eminentemente dialógico. Alzola (2007, p. 155), entre otros, defiende estas lecturas porque la narración "incorpora muchas voces diferentes, que hablan unas con otras y con otras voces fuera del texto, los discursos de la cultura y de la sociedad en general". Seleccionaron los libros tomando como criterio su calidad literaria, el interés de sus temas, su valor formativo, la capacidad lectora de los alumnos y otros criterios asumidos, en general, por la comunidad escolar y por la didáctica de la literatura: presencia de obras escritas por hombres y mujeres, autores nacionales y extranjeros, contemporáneos y antiguos; obras infantiles y juveniles actuales, clásicos de

Tabla 1. Obras leídas en el club de lectura

\begin{tabular}{|c|c|}
\hline Obra & Síntesis \\
\hline El no de Marina (Carmen Olaechea) & $\begin{array}{l}\text { Marina es una niña muy tímida que va de vacaciones a un pueblo pequeño donde conoce a Andrés, un } \\
\text { señor mucho más tímido que ella que, sin pretenderlo, le ayudará a vencer su problema, liberándose } \\
\text { finalmente los dos del mismo. }\end{array}$ \\
\hline $\begin{array}{l}\text { ¡No es tan fácil ser niño! (Pilar Lozano } \\
\text { Carbayo) }\end{array}$ & $\begin{array}{l}\text { Fernando es cambiado de clase a principios de curso y, en la nueva, Pedrito y sus seguidores le acosan } \\
\text { incesantemente por el tamaño de sus orejas. Poco a poco, con la ayuda de nuevos amigos, logra superar } \\
\text { esta situación. }\end{array}$ \\
\hline $\begin{array}{l}\text { Don Quijote (versión adaptada de } \\
\text { Vicens-Vives) }\end{array}$ & El libro recorre con relativa fidelidad los principales pasajes que aparecen en El Quijote original. \\
\hline $\begin{array}{l}\text { Luna de Senegal (Agustín Fernández } \\
\text { Paz) }\end{array}$ & $\begin{array}{l}\text { Khoedi, una niña senegalesa, viaja a España a reencontrarse con su padre, de quien luego se descubre que } \\
\text { ha sido inmigrante ilegal y las penurias por las que pasó. }\end{array}$ \\
\hline Las brujas (Roald Dahl) & $\begin{array}{l}\text { El niño protagonista de la historia y su abuela luchan contra todas las temidas brujas del mundo, reunidas } \\
\text { en un hotel para celebrar su convención anual, donde traman acabar con todos los niños del planeta. }\end{array}$ \\
\hline
\end{tabular}


la literatura universal adaptados a la competencia lectora de los alumnos y clásicos internacionales de la literatura infantil y juvenil.

\subsection{Instrumentos}

En el proceso de investigación se generaron diversos documentos, que constituyeron la base para el análisis de datos:

- Grabaciones en audio y en vídeo de las reuniones.

- Transcripciones de las sesiones y notas de campo elaboradas durante y después de cada sesión.

- El blog del club de lectura, en el que se incluyó un apartado para comentar los libros.

- Memoria exhaustiva de la experiencia, que incluye una revisión sistemática de las sesiones y de las fases del proceso de trabajo: planificación, acción, reflexión y metarreflexión.

- Aplicación de un cuestionario de satisfacción al alumnado al final del curso.

- Entrevistas semi-estructuradas realizadas a los participantes, a sus familias y al profesorado.

También se contó con observadores externos puntuales que reflexionaron sobre el diseño y evolución de la actividad. Con estos elementos se pudo obtener el máximo caudal de información y triangular y saturar los datos registrados en los diferentes soportes.

\section{Procedimiento}

El presente estudio se ha planteado como un estudio de caso en el que se ha llevado a cabo un proceso de investigación-acción. El objetivo último de los estudios de caso es conocer una unidad de análisis en profundidad con el interés de ofrecer ideas que contribuyan a mejorar esa realidad local y tomar decisiones informadas (Stake, 2005) que, a su vez, pueden ser de utilidad para otros casos más o menos afines (Gill, 2011). Para ello se elige una muestra pequeña, pero significativa y se profundiza en ella mediante técnicas de recogida de información variadas, que garanticen el rigor.

Se siguió un proceso de trabajo que constó de cuatro situaciones:

- planificación (previa a cada reunión);

- acción (durante la sesión);

- reflexión (durante y después de la reunión);

- metarreflexión (después de la reunión).

\section{Análisis}

Con posterioridad a la recogida de información, se procedió a organizar y analizar los datos, siguiendo pautas propias del análisis de contenido para los datos cualitativos y calculando frecuencias, porcentajes, puntuaciones medias y desviaciones típicas para los datos cuantitativos. La mayor parte de los datos recogidos son de tipo cualitativo, dada la necesidad de conocer el punto de vista de los participantes respecto a su experiencia como miembros del club.

Los resultados se han organizado sobre dos ejes: el modo de llevar a cabo las reuniones y el contenido de las mismas. En el primer caso, se han distinguido dos dimensiones de análisis: la planificación y desarrollo de las sesiones y la lectura dialógica; es decir, la estrategia didáctica seguida en

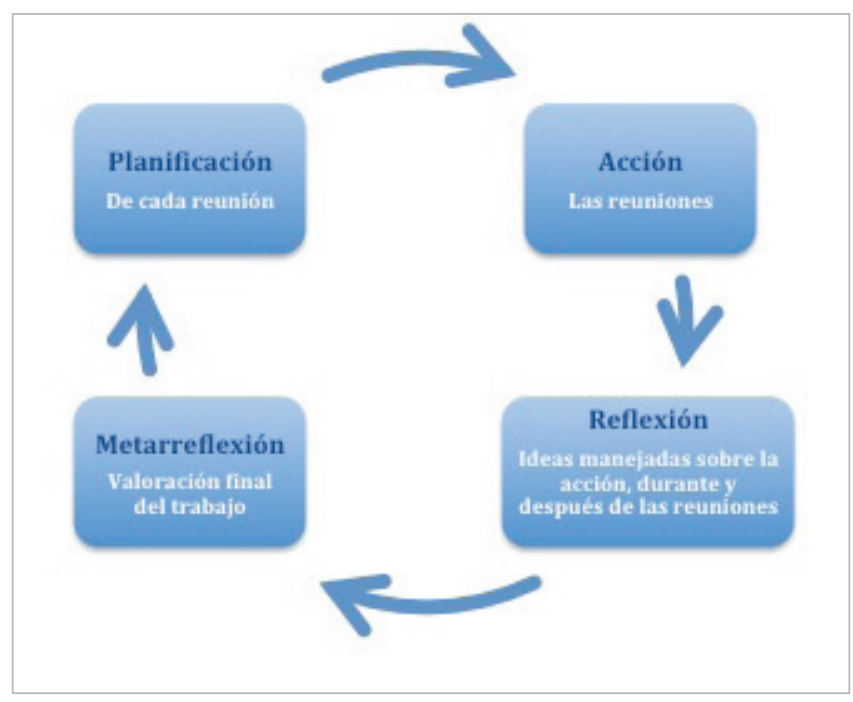

Figura 1. Proceso seguido en la sistematización de la investigación-acción

las tertulias literarias. Desde el punto de vista formativo o del contenido, se han planteado dos dimensiones más: la formación crítica, que se produce en la tertulia-debate y la educación en valores, que se trata de promover a través de las lecturas seleccionadas y su comentario oral.

\section{Resultados}

Los resultados de la investigación se presentan a continuación articulados en torno a las cuatro categorías anteriormente citadas.

\subsection{Planificación y desarrollo de las sesiones}

Una de las claves para que un club de lectura pueda cumplir con sus objetivos es contar con una buena planificación, a diferentes niveles. Varios son los aspectos destacados por los participantes que contribuyen al éxito del club y a facilitar los procesos de reflexión-acción:

- preparación minuciosa de cada reunión por parte de los coordinadores;

- estabilidad en la coordinación del club y la buena formación de sus responsables;

- adecuada selección de libros;

- existencia de normas de funcionamiento claras y asumidas por todos;

- creación de un clima que estimula la participación;

- utilización de un blog que permite hacer comentarios personales de las obras.

\subsection{Lectura dialógica}

Desde el punto de vista formal, un aspecto especialmente significativo es la realización de prácticas de lectura dialógica. Éstas suponen ir más allá de las prácticas tradicionales de lectura íntima y solitaria que merman la posibilidad de

Tabla 2. Ejes y dimensiones de análisis de los datos

\begin{tabular}{|l|l|}
\hline \multicolumn{1}{|c|}{ Ejes } & \multicolumn{1}{c|}{ Dimensiones } \\
\hline Forma & $\begin{array}{l}\text {-Planificación y desarrollo de las sesiones } \\
\text {-Lectura dialógica }\end{array}$ \\
\hline Contenido & $\begin{array}{l}\text {-Formación crítica } \\
\text {-Educación en valores }\end{array}$ \\
\hline
\end{tabular}




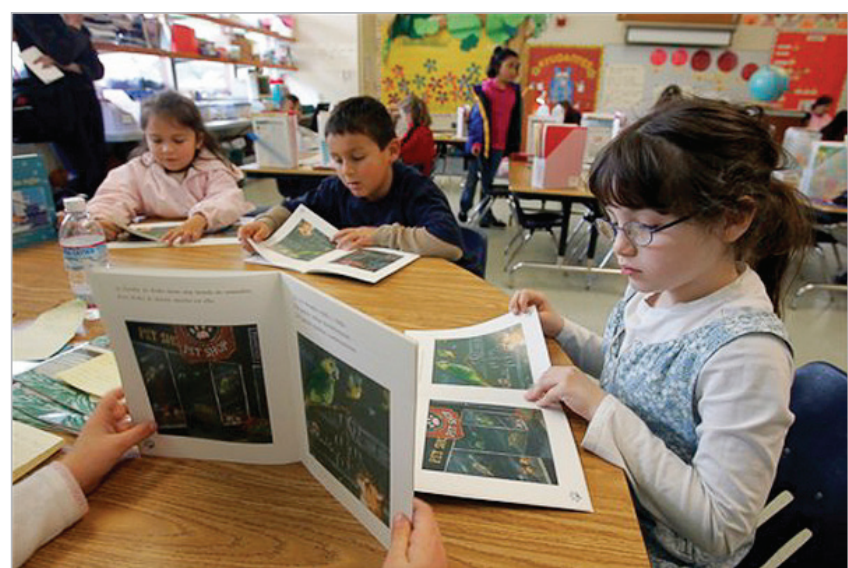

- "A mí los libros me gustan más sin imágenes, para imaginármelo"

discutir sobre las obras con otras personas. Así lo han expresado algunos alumnos al responder qué es lo que más les gusta del club": "Los comentarios, porque hablamos de los libros" $(02,11, C)$; "Las reuniones, porque me parecen interesantes" $(09,11, C)$. Los casos de lectura dialógica son muy numerosos y están presentes en las tres fases principales de las sesiones.

\section{Primera fase}

Tras la apertura de la sesión por parte de los coordinadores, se daba la palabra al alumnado, que opinaba libremente sobre la obra leída: calidad literaria, agrado personal, ilustraciones, etc. Después de un primer momento en el que intervenían varios participantes ofreciendo sus reflexiones, los coordinadores animaban al resto a que expusieran también su valoración de la obra.

\section{La lectura dialógica favorece el desarro- llo del pensamiento propio y del pensa- miento divergente del alumnado}

\section{Segunda fase}

Más tarde se pedía a los participantes que comentasen los momentos de la obra que les resultaron más interesantes o más llamativos, argumentando el por qué. Esto es muy importante, porque propicia una postura activa y curiosa en el lector:

\footnotetext{
Alumno: -Me causó mucha intriga cuando el protagonista estaba detrás del biombo y no sabía si lo iban a pillar, no se sabía si les iba a oler mal a las brujas...

[Risas]

Coordinadora: -¿Tú querías que lo pillasen?

Alumno: -No.

Coordinadora: -¿Por qué no querías que lo pillasen?

Alumno: -Porque me estaba gustando cómo era él y con su abuela y pensaba que si lo pillaban y lo convertían en ratón igual lo mataban o algo, o su abuela no lo podía distinguir.
}

En este caso, con la lectura de Las brujas, un miembro del club pone de relieve el interés que le generó un momento de tensión del libro: tras identificarse con el protagonista, teme por la vida del personaje en una situación tensa.

\section{Tercera fase}

En un momento posterior se pedía a los niños que expusieran las enseñanzas para la vida que aportaba el libro. Es posible destacar gran número de situaciones ricas en formación en valores y en educación crítica, pero, como guardan estrecha relación con el contenido de las lecturas, serán abordadas posteriormente.

\subsection{Formación crítica}

La lectura dialógica favorece el desarrollo del pensamiento propio y del pensamiento divergente del alumnado. El primero aparece en aquellas intervenciones de los niños en las que exponen libremente su opinión y la justifican a partir de la lectura, su experiencia, sus ideas o conocimientos previos. El pensamiento divergente se produce cuando los niños realizan reflexiones estimuladas por las aportaciones de otros compañeros y toman postura a partir de ellas.

Pensamiento propio. En este caso se han encontrado dos situaciones diferentes:

a) Expresión de la propia opinión y comprensión autónoma: el alumnado manifiesta libremente lo que piensa. Este ejemplo fue tomado de El no de Marina.

Alumno: -A mí los libros me gustan más sin imágenes, para imaginármelo. Y en este libro, la imagen que más me gusta es cuando está Andrés cantando y Marina lo ve.

b) Toma de conciencia: el alumno se apropia de una idea manifestada en la obra para hacerla suya; en este caso, es ofrecida por la coordinadora en el análisis del libro iNo es tan fácil ser niño!

Coordinadora: -¿ ¿Por qué crees que el autor habla de una paliza? Alumno: -Para que los niños vieran que por tener un defecto no hay que pegar a nadie.

Coordinadora: -Puede ser. Yo creo que el autor lo hace con otra intención, que es la de decir que peleando no se solucionan las cosas. ¿Os disteis cuenta de ese mensaje que trata de trasmitir el libro? (...) Varios alumnos: -Sí.

Pensamiento divergente. Dentro de esta categoría, se detectan dos situaciones distintas:

a) Construcción de un discurso alternativo: el alumno plantea un discurso alternativo al que se recoge en la obra o al manifestado por los compañeros o coordinadores, como en este caso, con El no de Marina.

Alumna: -El tema del libro también puede ser la apariencia que tiene Andrés de fuerte y cuando está con Marina creen que no puede ser tan tímido, que puede ser agresivo, pero, en cambio, es muy tímido y cuida bien de su hija y ella es más valiente siendo más pequeña; él tiene más fuerza física, pero es más valiente Marina.

Coordinador: -Las apariencias engañan, ¿no?

Alumna: -Sí.

b) Defensa de posiciones personales: el alumno argumenta sobre una postura personal que ha creado a partir de la lectura o del debate. Este ejemplo está tomado de Las brujas.

Coordinadora: -Cosas que criticarías al libro.

Alumna: -A mí no me gustaron las ilustraciones (...). Me parecieron muy infantiles.

En todos estos casos se aprecia que al alumnado se le da libertad para pensar por sí mismo, generando un pensa- 
miento crítico. Esto ha sido valorado muy positivamente por todos los participantes: -"Lo que más me gusta del club es que nos dejan expresar con libertad lo que nos parecen las cosas" (A4,12,C).

\subsection{Educación en valores}

En un club de lectura confluyen los valores que tienen los participantes con los que se encuentran implícitos y explícitos en las obras. Este contraste genera un crecimiento axiológico (valores) en el niño, que se ve nuevamente influenciado por los testimonios de los compañeros y coordinadores. Es algo que el alumnado aprecia y valora en las reuniones, y con lo que, además, aprende: -"Yo con ese libro entendí que me tenía que comportar mejor con todos mis compañeros de clase y del colegio" (O14,11,E).

A continuación reproducimos un momento de debate en una reunión que demuestra el interés de los estudiantes por las dimensiones éticas de las lecturas.

Alumna: -Cuando los chicos esos vienen y destrozan el jardín, están destrozándolo todo y Marina dice "no".

Coordinadora: - ¿Por qué ella grita "no"? ¿Qué sentimiento es el que tiene que le hace gritar "no" y superar su timidez? O por lo menos en ese momento parece que supera su timidez. ¿Cómo se llama ese sentimiento? ¿Cómo se siente ella?

Alumno: -Yo creo que se siente enfadada porque le da pena de Andrés, porque le están destrozando el jardín y él está ahí en la ventana; yo creo que está llorando y esperando a que se fueran.

[Tratan de acertar un adjetivo para ese pensamiento, hasta que una alumna lo dice].

Alumna: -Impotente.

En este momento del comentario del libro El no de Mari$n a$, se percibe el interés y el sentimiento de rechazo que ha despertado en una alumna un acto vandálico llevado a cabo por unos adolescentes. En todas las obras leídas se han producido situaciones similares que han permitido intensos debates sobre lo que está bien o no, generando una red de interacciones en las que se funde la formación transversal y la literaria y lingüística. La tabla 3 recoge aspectos relacionados con la educación en valores abordados en los diferentes coloquios.

\section{El club de lectura desde la biblioteca es- colar puede contribuir al desarrollo de la lectura por placer y favorecer el pensa- miento crítico ante la lectura y la educa- ción en valores}

\section{Discusión y conclusiones}

Los resultados obtenidos apoyan la hipótesis planteada. La implementación de un club de lectura desde la biblioteca escolar puede contribuir al desarrollo de la lectura por placer $y$, al mismo tiempo, puede favorecer el pensamiento crítico ante la lectura y la educación en valores. Aunque es cierto que en el proceso de lectura individual los niños se suelen identificar con los protagonistas de las aventuras literarias (Patte, 2008), en el proceso de lectura colectivo, en la tertulia, tienen la oportunidad de tomar la palabra y aportar sus valores a la lectura (Chambers, 2007). Así se educan el sentido estético, la dimensión ética y las emociones (Camps, 2011). El siguiente testimonio de una participante puede ser suficientemente ilustrativo: -“Me gusta mucho venir al club de lectura porque ahora leo más y me gusta leer. Antes leía con mi madre, pero no me gustaba" $(\mathrm{A} 15,12, \mathrm{E})$.

Tabla 3. Aspectos de educación en valores abordados

\begin{tabular}{|c|c|}
\hline Obra & Aspectos abordados \\
\hline El no de Marina & $\begin{array}{l}\text {-La timidez y cómo la superan los protagonistas } \\
\text {-La dificultad para expresar los sentimientos y lo positivo que resulta hacerlo } \\
\text {-La impotencia ante situaciones que se consideran injustas } \\
\text {-Las apariencias pueden engañar } \\
\text {-La capacidad de cambio de las personas y el potencial de la autocrítica para la mejora } \\
\text {-El amor y las buenas relaciones en familia }\end{array}$ \\
\hline ¡No es tan fácil ser niño! & $\begin{array}{l}\text {-El sufrimiento de un niño acosado y sus sensaciones y preocupaciones } \\
\text {-Papel de los acosadores en los grupos y el de los que observan y animan cómplicemente estos comportamientos } \\
\text {-Cómo se puede prevenir y corregir el maltrato en la escuela } \\
\text {-Papel de los educadores ante situaciones de acoso } \\
\text {-Papel de la violencia en la resolución de conflictos } \\
\text {-El respeto y la convivencia como elementos de cohesión social }\end{array}$ \\
\hline Don Quijote & $\begin{array}{l}\text {-La obsesión como algo negativo } \\
\text {-La locura y sus problemas } \\
\text {-Uso de expresiones malsonantes en libros de literatura infantil } \\
\text {-El valor de la perseverancia }\end{array}$ \\
\hline Luna de Senegal & $\begin{array}{l}\text {-La dureza de la inmigración, legal e ilegal } \\
\text {-La necesidad de las personas de trabajar y vivir con dignidad } \\
\text {-Interculturalidad } \\
\text {-Autodisciplina para leer un libro cuando no resulta agradable } \\
\text {-La capacidad de reflexión de las personas como cualidad que se puede cultivar } \\
\text {-La importancia de ayudar a las personas vulnerables } \\
\text {-El inigualable cariño que proporcionan los abuelos }\end{array}$ \\
\hline Las brujas & $\begin{array}{l}\text {-El amor en familia, sea cual sea su forma } \\
\text {-Los caprichos de los niños hoy y cómo debe actuarse ante ellos } \\
\text {-El engaño como algo negativo } \\
\text {-La importancia de seguir siendo lectores en la etapa de educación secundaria }\end{array}$ \\
\hline
\end{tabular}




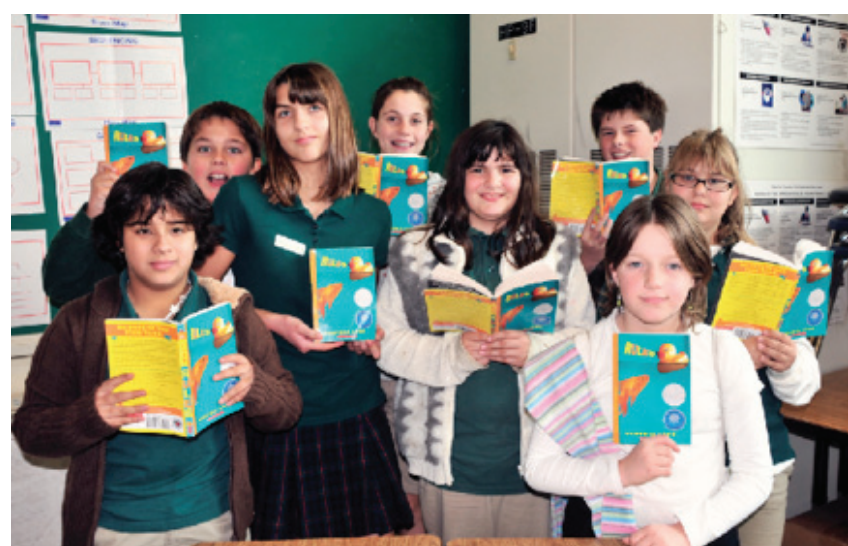

La discusión en grupo estimula la participación de los alumnos

La interrelación de las cuatro dimensiones que articulan los resultados de la investigación puede constituir una base adecuada para construir una práctica exitosa de animación a la lectura, que fomenta el gusto lector por las razones siguientes:

En primer lugar, la planificación y estructuración minuciosa de las sesiones, siguiendo procesos de investigación-acción, permite configurar un clima en el grupo que estimula la participación de los alumnos, la selección adecuada de los textos y la formación constante de los coordinadores de la actividad. Estos aspectos han sido elementos clave para favorecer la asistencia y la implicación creciente de los participantes en una actividad de carácter voluntario. Por su parte, el blog ha permitido a los miembros del club interaccionar entre sí compartiendo su experiencia lectora: comentando impresiones, destacando pasajes de la obra, emitiendo valoraciones, etc. Esta tecnología, puesta al servicio del club de lectura, es una herramienta complementaria a las tertulias muy valiosa. En otros clubs de lectura, el empleo de medios tecnológicos puede ser un elemento determinante, como muestra el estudio de la Fundación Germán Sánchez Ruipérez (2012) con el uso de libros electrónicos o el estudio de Manso-Rodríguez (2012) con redes sociales. En el caso analizado, el blog ha jugado un papel complementario.

Los participantes han crecido axiológicamente, formulando juicios respecto a los valores de las obras y sus implicaciones sociales

En segundo lugar, se constata el gran potencial educativo del enfoque dialógico para favorecer la formación crítica de lectores y la lectura por placer. Aunque es posible que el alumnado pueda desarrollar individualmente y por escrito ciertas habilidades de lectura crítica, tiene un enorme interés la práctica de estrategias didácticas innovadoras asentadas sobre el diálogo crítico como método de trabajo (Chambers, 2007; Fecho; Coombs; McAuley, 2012), la cooperación y la interacción entre el alumnado y los coordinadores. Además, desde el punto de vista lingüístico-literario, una tertulia literaria dialógica permite acercar al alumnado a una actividad de ocio como la lectura que, en muchos ca- sos, resulta novedosa. Esto tiene un valor especial cuando los estudiantes están privados de un ambiente motivador por razones socio-culturales, como es este caso, y cuando se constata que las prácticas dialógicas son las que tienen una mayor influencia transformadora en los participantes (Robinson, 2011) y que, habitualmente, las prácticas escolares no responden a este planteamiento (Reznitskaya, 2012).

En tercer lugar, se comprueba que dar la opinión sobre una lectura y debatir sobre la misma favorece la comprensión de una obra literaria, en el sentido en el que ésta se define en el estudio de la Fundación Germán Sánchez Ruipérez anteriormente citado: comprender las tramas, profundizar en los personajes y temas y enriquecer o ampliar conscientemente la lectura conectando los contenidos del relato con temas y competencias específicos suscitados por él. Estos tres niveles de lectura se potencian en las sesiones del club y favorecen el desarrollo del pensamiento crítico: los estudiantes pueden ponerse en el lugar de los personajes, criticar aspectos de un texto o una parte de la lectura con argumentos que están en un proceso de análisis y de reelaboración.

En cuarto lugar, se constata que los participantes han crecido axiológicamente (en valores), formulando juicios respecto a los valores de las obras y sus implicaciones sociales. Esto es importante ya que la reflexión y el debate sobre los valores implícitos y explícitos de los relatos no constituye algo complementario a la lectura, sino que, por un lado, la "enriquece o amplía" y, por otro, estimula la implicación e interés hacia la misma y hacia las interpretaciones de los compañeros y personas adultas (Blum et al., 2010).

Además de los aspectos reseñados, hay que señalar la contribución positiva del club de lectura escolar a la mejora de la competencia lectora, tal y como pusieron de manifiesto los profesores del alumnado participante y sus familias en los cuestionarios aplicados. Finalmente, hay que destacar su aportación al desarrollo de la educación literaria, que supone una intervención en campos estrechamente vinculados: ayudar al alumnado a descubrir la lectura como experiencia satisfactoria, aprender a construir el sentido del texto y familiarizarse con sus características discursivas, textuales y lingüísticas (Zayas, 2011).

\section{Notas}

1. Los testimonios del alumnado permiten identificar el sexo del participante (O para alumnos; A para alumnas), su identidad $(1,2,3 \ldots)$, edad $(11,12 \ldots)$ y la técnica empleada $(0$ : observación; E: entrevista; C: cuestionario).

\section{Bibliografía}

Alzola, Nerea (2007). "Literatura infantil y educación ética: análisis de un libro". Revista de psicodidáctica, v. 12, n. 1, pp. 153-166. http://www.ehu.es/ojs/index.php/psicodidactica/article/ view/215/211

Arana-Palacios, Jesús; Galindo-Lizaldre, Belén (2009). Leer y conversar. Una introducción a los clubes de lectura. Gijón: Trea. ISBN: 9788497044493

Atwell, Nancie (2007). The reading zone: how to help kids become skilled, passionate, habitual, critical readers. Nueva York: Scholastic. ISBN: 9780439926447 
http://gec.kmu.edu.tw/ /c/ecorner/eBook/The\%20 Reading\%20Zone.pdf

Baró, Mònica; Mañà, Teresa (2013). "Bibliotecas escolares: ¿un valor en alza?". El profesional de la información, v. 22, n. 2, pp. 106-112.

http://bd.ub.edu/pub/mana/sites/bd.ub.edu.pub.mana/ files/EPI,106-112.pdf

http://dx.doi.org/10.3145/epi.2013.mar.02

Blum, Irene H.; Koskinen, Patricia S.; Bhartiya, Purnima; Hluboky, Sandra (2010). "Thinking and talking about books: using prompts to stimulate discussion". The reading teacher, v. 63, n. 6, pp. 495-499.

http://dx.doi.org/10.1598/RT.63.6.6

Camps, Victoria (2011). El gobierno de las emociones. Barcelona: Herder. ISBN: 9788425427442

Carreño, Óscar (2012). Clubes de lectura. Barcelona: editorial UOC, colección El profesional de la información, n. 11. ISBN: 9788490292389

Cassany, Daniel (2008). "Llegir críticament, all Ilarg del currículum. Presentació". Temps d'educació, n. 34, pp. 7-10. http://www.publicacions.ub.edu/refs/indices/06977.pdf

Chambers, Aidan (2007). Dime. México: FCE. ISBN: 9789681684532

Fecho, Bob; Coombs, Dewan; McAuley, Sean (2012). "Reclaiming literacy classrooms through critical dialogue". Journal of adoslescent \& adult literacy, v. 55, n. 6, pp. 476-482. http://dx.doi.org/10.1002/JAAL.00057

Fundación Germán Sánchez Ruipérez (2012). Ebook-18: Los lectores niños y jóvenes y los libros electrónicos. Peñaranda de Bracamonte: Centro de Desarrollo Sociocultural.

http://www.territorioebook.com/recursos/vozelectores/ menos18/informe_lectores_menos_18.pdf

Gómez-Hernández, José-Antonio (2013). “Unir educación y bibliotecas: la evolución de un reto permanente". El profesional de la información, v. 22, n. 2, pp. 101-105.

http://www.elprofesionaldelainformacion.com/ contenidos/2013/marzo/01.pdf

http://dx.doi.org/10.3145/epi.2013.mar.01

Gill, T. Grandon (2011). Book informing with the case method. Londres: Informing Science Press. ISBN: 9781932886443 http://grandon.com/publications/CaseMethod.pdf

Gritter, Kristine (2011). "Promoting lively literature discus- sion". The reading teacher, v. 64, n. 6, pp. 445-449. https://crmsliteracy.wikispaces.com/file/view/Promoting $+L$ ively+Literacy+Discussion.pdf

http://dx.doi.org/10.1598/RT.64.6.7

Jiménez-Fernández, Concepción; Cremades-García, Raúl (2013). Bibliotecas escolares. Barcelona: EPI-UOC, n. 22. ISBN: 978840298862

Manso-Rodríguez, Ramón-Alberto (2012). “Bibliotecas: fomento de la lectura y redes sociales: convirtamos amigos en lectores". El profesional de la información, v. 21, n. 4, pp. 401-405.

http://eprints.rclis.org/17310/1/401-405.pdf

http://dx.doi.org/10.3145/epi.2012.jul.12

Mata, Juan (2008). Animación a la lectura. Hacer de la lectura una práctica feliz, trascendente y deseable. Barcelona: Graó. ISBN 9788478276813

Olson, David (2009). "Education and literacy". Infancia y aprendizaje, v. 32, n. 2, pp. 141-151.

http://dx.doi.org/10.1174/021037009788001824

Patte, Geneviève (2008). Déjenlos leer. Los niños y las bibliotecas. México: FCE. ISBN: 9789681676698

Robinson, Andrew (2011). "Thinking better, whatever one thinks: Dialogue, monologue and critical literacy in education". Critical literacy: Theories and practices, v. 6, n. 1, pp. 21-35. http://goo.gl/Z344Oz

Reznitskaya, Alina (2012). “Dialogic teaching. Rethinking language use during literature discussions". The reading teacher, v. 65, n. 7, pp. 446-456.

http://www.montclair.edu/profilepages/media/370/ user/2012-Dialogic_Teaching-RT.pdf http://dx.doi.org/10.1002/TRTR.01066

Stake, Robert E. (2005). Investigación con estudio de casos. Madrid: Morata. ISBN: 9788471124227

Whitehead, Jack (2009). "Generating living theory and understanding in action research studies". Action research, v. 7, n. 1, pp. 85- 99.

http://www.actionresearch.net/writings/jack/jwartheory0309. $p d f$

http://dx.doi.org/10.1177/1476750308099599

Zayas, Felipe (2011). La educación literaria. Cuatro secuencias didácticas. Barcelona: Octaedro. ISBN: 9788499213293

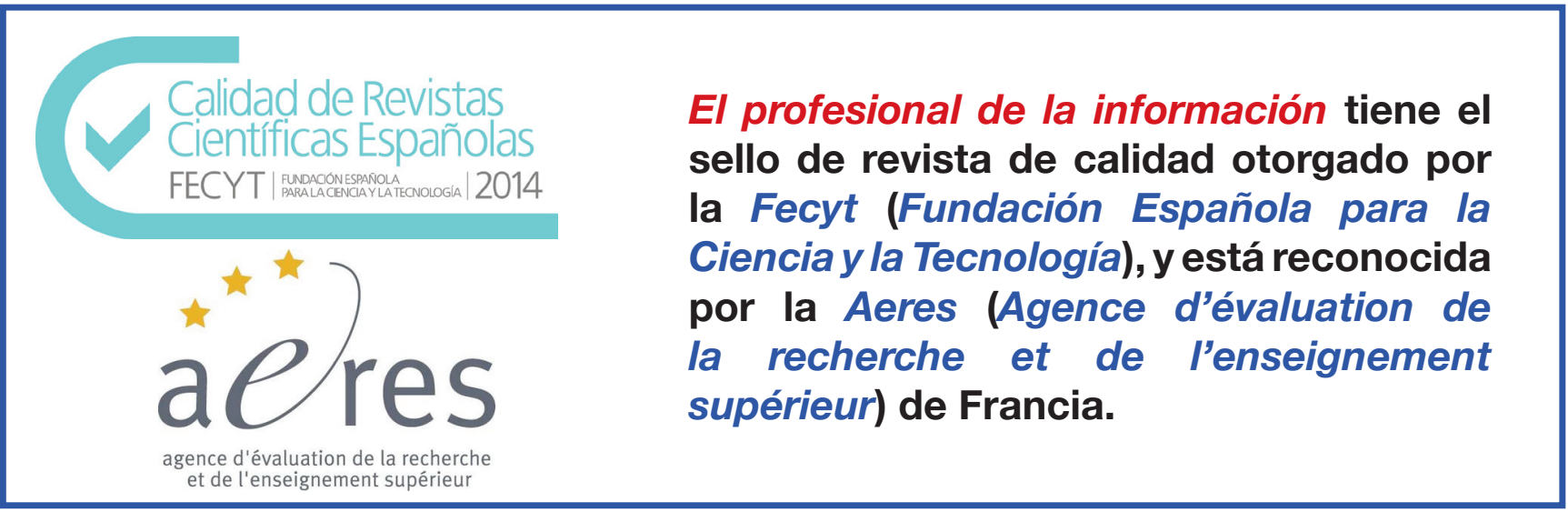




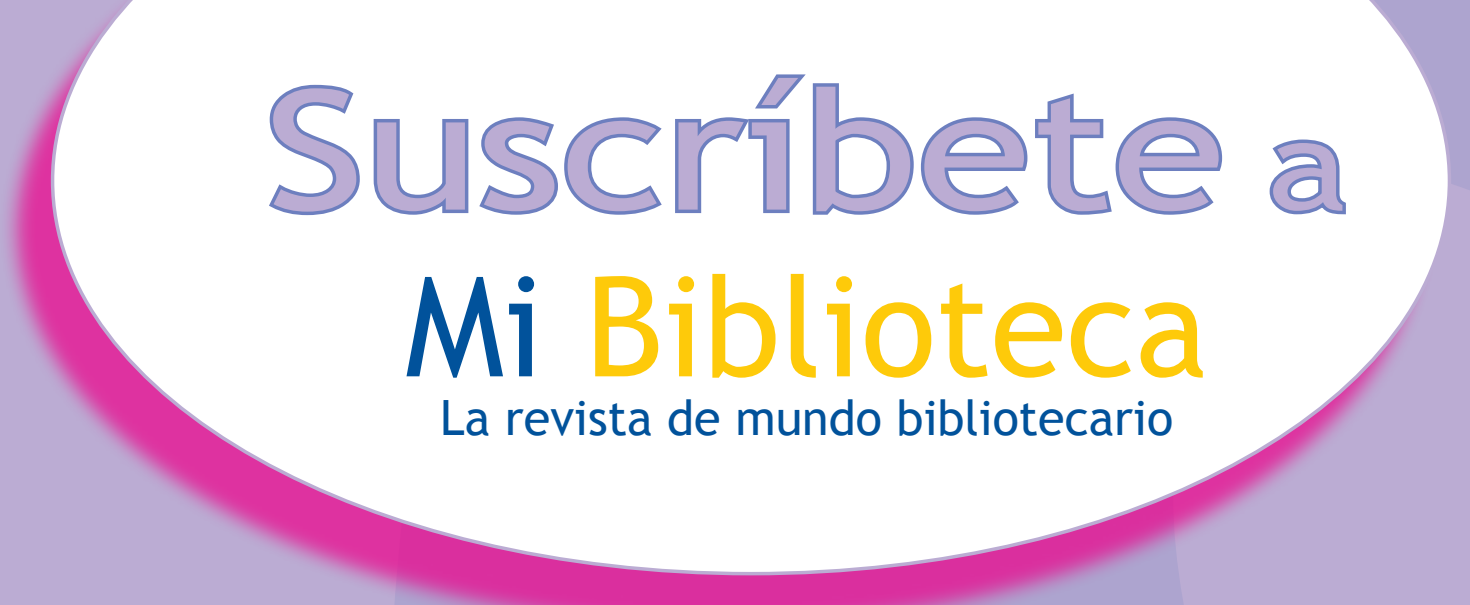

Ofrecemos la suscripción gratuita por un año a la revista Mi Biblioteca a todas aquellas bibliotecas que ofrezcan a sus usuarios y amigos la posibilidad de ser socios de la Fundación Alonso Quijano (entidad sin ánimo de lucro editora de la revista)

y consigan al menos 5 socios.

Y recibirás de modo gratuito este manual de referencia para

\section{bibliotecarios}

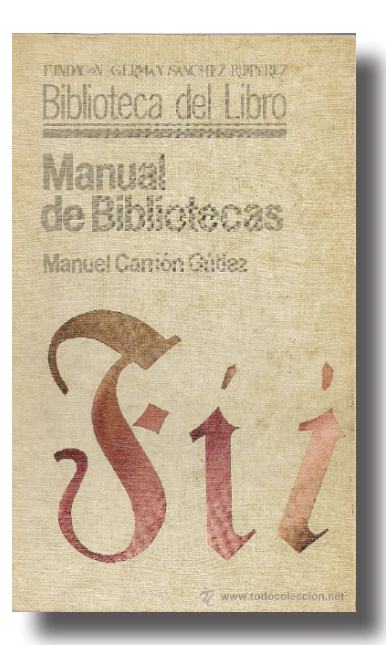

www. mibiblioteca.org 952235405

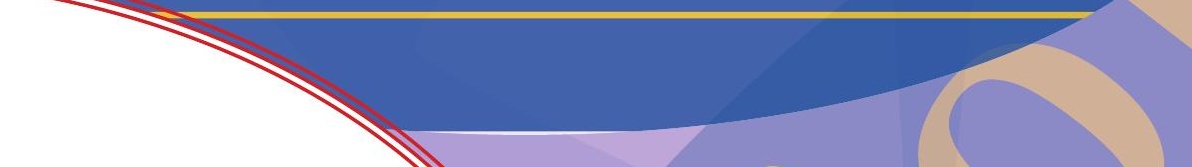

